\title{
Freedom Without Choice?
}

\section{Gottfried Seebaß}

\section{Introducing the Problem}

"Freedom's a marvellous name. That's why you're so anxious to make use of it. You think that, if you call imprisonment true freedom, people will be attracted to the prison. And the worst of it is you're quite right. The name counts more with most people than the thing. They'll follow the man who repeats it most often and in the loudest voice." This quotation from a novel by Aldous Huxley castigates an extreme form of verbicide that has been well-known for long, though in a less extreme form, from religious, political or economic propaganda. Realizing that "freedom" is considered highly valuable by almost everyone, various authoritative persons and institutions try to insinuate that men are "really free" only if they are bound by certain goals or ways of life, even if this implies a severe restriction of personal options and choices. The critical point is not the existence of restrictions as such. Obviously, human beings are subject to all sorts of restrictions - physical as well as mental, natural as well as cultural - which are not harmful or relevant to their freedom at all. The critical point is that even severe restrictions normally thought to be harmful, or paradigm cases of deprived freedom, are proclaimed to be utterly insignificant to or even necessary for "real freedom".

Undoubtedly, this is a misuse of words in many cases. But is it a misuse generally? Couldn't it be the case that certain restrictions, even severe restrictions of options and choices, or bare necessities, are not harmful to us in the least, but rather highly

'A. Huxley (1936), 123

G. Seebaß (Z)

Department of Philosophy, University of Konstanz, Konstanz, Germany

e-mail: Gottfried.Seebass@uni-konstanz.de 
valuable and conducive to or, at the very least, reconciled easily with personal freedom? Apparently, it is not always a benefit to be confronted with a multitude of alternative options. "The wider the choice, the greater the trouble" is a well known proverb in German. More radical still is the diagnosis made by Dostoevski's Grand Inquisitor. ${ }^{2}$ According to him, freedom is a "Greek gift" to mankind since most people are unable to bear the consequences of individual autonomy and flee readily into blind obedience to religious authorities. Similarly, though with a critical intent, Erich Fromm diagnosed a strong tendency of modern man towards a political and social "escape from freedom" due to a felt inability to live up to the modern ideals of autonomy and individualism.

Of course, escaping from freedom into restraint is not the same thing as being free in spite of, or even because of, being restricted. Still, there are many writers ready to apply the very concept of "freedom" even to cases where choice is restricted severely. Many philosophers (e.g., those who are convinced theoretically that determinism is true, or might well be true) continue to talk of "freedom" in practical matters despite the fact that, by that hypothesis, there are no alternative options at all which could be chosen objectively. Are we to say that all of this is a misuse of words? Or is "freedom without choice" a real, respectable possibility or even, on closer inspection, the only kind of freedom accessible to, or advisable for, human beings at all?

\section{The Concept of Freedom}

To tackle this question, one has to look first at the concept of "freedom". Here I will take a shortcut, drawing from the results of my extended earlier research on these matters. ${ }^{4}$ In the most general sense, being "free" means much the same as being "unhindered". Hobbes and Schopenhauer have argued for this, ${ }^{5}$ and their diagnosis is confirmed by ordinary language. More specific senses of "freedom" are subsumed easily. These refer in particular to the classical notions of "freedom of action" and "freedom from constraint" developed by Greek philosophy. Most forms of social, political and economic freedom are covered by these. Freedom of action means being unhindered in one's position to act as one wants or wills to act. Freedom from constraint is more complex, meaning in a broad sense almost the same as being unhindered purely and simply but having several narrower meanings (already hinted at by Aristotle ${ }^{6}$ ) that overlap partly with what we would call "freedom of will".

${ }^{2}$ F.M. Dostoevski The brothers Karamazov, bk. V, ch. 5.

E. Fromm (1941), chs. 5-6.

G. Seebaß (1993, 1997, 2006, 2007).

${ }^{5}$ See Hobbes, Th. (1966), vol. III, 196; vol. IV, 273f., 275f.; vol. V, 367f., and A. Schopenhauer (1977), 43f

${ }^{6}$ Aristotle, Ethica Nicomachea, bk. III, 1-2; compare in addition G. Seebaß (2007), 124-126, 213-216.
Freedom of will is another special case branching again into various subcases, all of which are cases of being unhindered in forming one's will.

However, central to all forms of freedom is the concept of "hindrance" itself. Clearly, this is a very general notion to be specified best by the questions of what is hindered in what and by what. A river that is not hindered in its flow by dams or embankments is said to "flow freely". A paralyzed or tied man is "unfree" because he is hindered to move as he wants to move by abnormal (internal or external) impediments. The hindrance need not extend to every part or aspect and need not be absolute. Still, it must be significant. Common to all subcases is the idea that something or somebody is restrained severely from evolving, living, or existing in ways which are "natural" or "essential" to it, or to him or her, and therefore should not be eliminated. Hence, whether, in what respects, and to what degree something is free or unfree has to be judged with reference to two dimensions: (1) the relevant standards of "naturalness" and (2) the relevant realm of theoretical possibilities that are actually closed or open.

Roughly, the greater the number of open possibilities, the lesser the hindrance and the greater the freedom. However, possibilities that do not touch on the relevant "nature" can be ruled out as inessential. Most of the infinite number of actions I might envision but actually cannot do are irrelevant to my freedom as I do not and will never care about them in the least. Having decided spontaneously and on my own to go to a concert tonight, for example, I do not feel restricted in the least by the fact that, in doing so, I am able no longer to watch to the 80th episode of a trivial soap opera on television. Conversely, the fact that my TV set offers 80 programs to me today instead of the 2 programs I used to have does not enhance my freedom 40 -fold if I do not care about the 78 additional programs. Thus freedom implies open pos sibilities but only possibilities "essential" or "natural" to the person in question.

\section{Cutting the Possibilities Criterion}

Now, if the range of alternatives actually open is diminished severely, or even reduced to one in the determinist case, the possibilities criterion appears to fail. Hence, it is doubtful whether the concept of freedom makes any sense in these cases. In an attempt to evade this unwanted conclusion, some writers have taken the radical course of dismissing the criterion completely. Theologians such as Origen and Molina contrived an argument, revived in 1969 by Harry Frankfurt, which is intended to show that the inexistence of open alternatives is not detrimental to freedom. ${ }^{7}$

${ }^{7}$ See in particular Origen, De principiis, bk. II, 9; H.S. Benjamins (1994), 113ff., 138ff.; L. de Molina (1988), 24ff,, 168ff.; L.T. Zagzebski (1991), ch. 5; R. Gaskin (1993), and H. Frankfurt (1988), ch. 1 
More recently, David Widerker constructed a different argument to the same effect. ${ }^{8}$ However, I am convinced that none of these efforts succeed. ${ }^{9}$

Other writers have taken a less radical course. Acknowledging the significance of the possibilities criterion as such, they try to show that this criterion can be assigned a meaning weak enough to be compatible with a severe reduction in, or even the complete inexistence of, objective alternatives. Some authors have argued that meaningful talk of "personal freedom" is confined to the idea of possibilities open in a merely subjective or epistemic sense..$^{10}$ But this is implausible, as was already argued convincingly by Locke." A man who is locked in a room and stays willingly while erroneously believing that he also has the option to leave is not free to do so in fact. The same holds true of a man who is convinced, when reflecting theoretically, that all occurrences in the world (including his own activities, mental as well as physical) are determined completely and strictly, but who is, nevertheless, unable or unwilling to give up, or resist, his reemerging erroneous beliefs to the contrary whenever he finds himself engaged in deliberating and trying to decide on practical matters. Accordingly, most adherents of the "compatibilist" interpretation I have described here do not deny that meaningful talk of "freedom" implies a commitment to possibilities open not merely in an epistemic or subjective sense but open objectively and ontologically. However, following the lead of St. Augustine, ${ }^{12}$ they try to show that this can be reduced to the conditional analysis of practical possibility which does not rely, allegedly, on the premise, or tacit presupposition, that alternative courses of acting and forming the will are open in fact but refers to such alternatives only in a hypothetical or (in the determinist case) counterfactual sense.

However, despite the respectable authority of St. Augustine and all of his followers in theology and philosophy as well, the conditional analysis fails. First, in its classical form, it is no analysis of practical possibility at all, as it does not extend to its relevant modal sense. But if one proceeds to fill this conceptual gap, one comes up with a notion of possibility that does imply alternatives that in fact are open, contrary to what was intended. ${ }^{13}$ Second, there is the problem of freewill. If intentional actions

\section{${ }^{8} \mathrm{D}$. Widerker (2006)}

${ }^{9}$ For a succinct critique of the Origen-Molina-Frankfurt argument, see G. Seebaß (2006), 217, 364 Widerker's argument is more sophisticated in some respects. But both of his new scenarios ("Z-Persons" and "Brain-Malfunction-W", cf. 169ff.) depend on tacit premises which will lead, spelled out completely, straight into the dilemma either to deny that the person in question is free or to acknowledge the existence of open alternatives, contrary to what was intended.

${ }^{10}$ For an early example of this general line of thought, compare C.W. Snell (1789), 56-58. More detailed and philosophically influential are the arguments given by M. Planck (1965), 139--168, 301-317, 334-349, 350-362, and D.M. MacKay (1967).

${ }^{11} \mathrm{~J}$. Locke, An essay concerning human understanding, bk. II, ch. $21, \S 10$

${ }^{12}$ See A. Augustinus, De libero arbitrio, bk. III: 2,14-4,41, and De civitate Dei, bk. V, 9-10. Many of the contemporary "compatibilists" in philosophy believe, erroneously, that the conditional analysis was invented in 1912 by G.E. Moore (cf. 1965, ch. VI). In fact, however, there are many predecessors in theology and philosophy as well (cf. G. Seebaß 1997, 240; 2006, 175f., 221, 245f., 364-366).

${ }^{13}$ For an extended argument to this effect and a detailed critique of the conditional analysis, see G. Seebaß (2006), ch. 7. and forbearances count as "possible" merely in view of their being conditional on the relevant will, what about the possibility of willing itself? Trying to answer this critical question simply by an analysis of the same kind, applied on a higher level, would lead its advocates straight into an infinite regress. Accordingly, following the lead of Augustine once more, many philosophers take refuge in the position that the will in general, or at least any will resulting from reflection and deliberation, is free ipso facto and that, as a consequence, it is unnecessary to recur to the possibilities criterion once we have reached the volitional level. But this sweeping move, which looks evasive from the start, certainly does not fit many empirical cases of forming the will where it is more than doubtful that the resulting will is free, no matter how sophisticated the processes of deliberation and reflection involved Moreover, neither Augustine's argument nor (to my knowledge) any other general argument is sufficient to prove that the will is free ipso facto. ${ }^{14}$

Hence, our situation is this. Irrespective of whether we try to apply the possibilities criterion to wilful, intentional action or to willing itself, severely restricting the range of open alternatives (or eliminating them completely in the determinist case) implies that the possibilities criterion is cut. And, as this criterion cannot be dismissed outright, contrary to the radical claims of some philosophers and theologians, this means that the relevant forms of freedom appear to be reduced or eliminated, too. Consequently, talking of "freedom without choice" does not seem to refer to a real, respectable kind of freedom, but rather to be a misuse of words.

\section{Advancing the Criterion of "Naturalness"}

Still, this is not the end of the story. The possibilities criterion is not the only one; there is also the criterion of "naturalness" or "essentialness". Hence, one migh think that this criterion could be sufficient in and of itself to confirm freedom even in cases where the possibilities criterion fails. To this idea, philosophers like Rousseau ${ }^{15}$ would respond that it is the very ability to choose and decide between alternatives open objectively that is constitutive of human nature. But this argument rests on a questionable, highly demanding interpretation of "naturalness" that certainly is not self-evident. So let us grant for the moment that it is possible to meet the criterion of "naturalness" or "essentialness" apart from our first criterion. Suppose, accordingly, that we can demonstrate for a particular person that all of the possibilities closed to him, or her, at a particular time are "inessential". Given this fact, we may well call this person "free" in what she, or he, actually wills and does, even if the range of

${ }^{14}$ For a critique of Augustine's formal argument to the effect that volition is free ipso facto, see W Rowe (1964), and G. Seebaß (1997), 239ff. For a detailed critique of the idea of saving volitional freedom by relying on the mere fact of extended, sophisticated deliberation and reflection, see $\mathrm{G}$. Seebaß (2006), 223-238.

is J.-J. Rousseau (1977), 67, cf. also (1990), 236-241. 
alternative courses of acting or forming the will are restricted severely or even reduced to one. However, what possibilities are "inessential" or "essential" to a particular person at a particular time?

Surely we cannot say purely and simply that this depends on what the person actually wants or wills. For, as noted before, even our considered, reasoned will is not "essential" ipso facto and is likely to be "inessential" if formed, for example, under pressure, in ignorance or without reflection on concurring wants and volitions. If so, what about turning to the opposite position? Is it possible to ignore the volitional states of people completely and to state from an independent, external position what is, or should be, considered "natural" or "essential" for someone (similar to what we do when describing a river as "flowing freely")? This would amount to the claim that there are objective, idealized standards of what befits people, taken individually or generically, in leading an "essential" form of life. However, is there anyone able to tell, or to define in general, what belongs to the "essence" of persons independent of their subjective mental states including volitions? Even the most experienced psychotherapists, closest personal friends, or most perceptive parents taking care of us during infancy cannot claim to "know better" what we "really want or will" independent of taking into account our actual volitional states and attitudes or, at the very least, independent of looking forward to our eventual reflective consent. Thus subjective volition cannot be given up as a necessary condition of personal "essentialness" although it needs to be strengthened substantially for it to become sufficient.

Trying to give a full account of "volitional essentiality", taken individually or generically, is a demanding task that I cannot take up in detail here. Rather, I shall confine myself to just the one aspect of this multifaceted problem most central to our present theme. If we are to make any positive sense of "freedom without choice", we need to specify what is "essential" to a particular person - lifelong or for some particular time - by referring (among other things) to a qualified class of volitions. But can this class be singled out independently of referring to relevant personal choices? If so, speaking of "freedom without choice" in relevant cases can be justified; otherwise, it is spurious. Hence we must look more closely at the external influences and internal processes behind existing volitions. This requires two crucial steps. First, we must look for cases where personal choice seems to be eliminated or restricted severely, but where it is not in doubt - measured against the standards of "naturalness" or "essentialness" - that all such cases are positive instances of acting or willing freely. Thereafter, we have to check in a second step whether there really are no choices involved, although such choices may not be visible at first glance or may be potential rather than actual.

\section{Freedom Dependent on Actual Choice}

Obviously, there are many instances of "free action" which depend on actual choices made at an earlier time. Once in the air, a parachutist has no choice but to go down to earth. But if he has chosen to do so freely, we may well classify his entire movement as a "free jump". Once I have signed a contract or political declaration, I have no choice but to live with the consequences. Still, I am free in doing so, provided I have foreseen all relevant consequences and have signed the document freely. Similarly, a man may well lead an "essential" form of life if he has decided freely, e.g., to live within the narrow confines of a heavenly spacelab or of a monastery on earth, even if this implies a severe restriction of options. Strictly speaking, almost everything we do will lead in consequence to restrictions of later options, some of which will be severe but not harmful to our personal freedom as we have chosen freely to bind ourselves to them. Apparently, by choosing and deciding freely for a particular course of action or confining ourselves freely to a particular form of life, we can define for the moment, or for some extended stretch of time, what is "essential" or "inessential" to us.

This also applies, mutatis mutandis, to relevant cases of willing freely. By forming an intention or deciding definitely for a particular goal, we settle the question of which option within a given class of alternatives we should choose. Henceforth we are committed to certain intended ends and means. These, then, guide our actions, practical deliberations, and other processes of forming the will by screening them off, for example, from concurring wants or distracting situational features. ${ }^{16}$ Accordingly, due to the existing commitments, the relevant range of volitional states and attitudes is restricted or reduced to one (in the determinist case) although these restrictions need not be "unnatural" and "inessential" provided that they have resulted from relevant choices made at an earlier time. This is confirmed by everyday experience. As has already been noted perceptively by Hegel, ${ }^{17}$ entering willingly into a relation of friendship or love may result in a mutual adaptation of will compatible with or conducive to personal freedom. Similarly, having decided freely to join a sports club, political party, or religious community, some people come to identify themselves with the constitutive norms and goals of these institutions. Although the resulting volitional restrictions need not be absolute, they are severe and manifest themselves, at the very least, as a marked bias or tendency influencing future deliberations and other processes of forming the will. Sometimes such restrictions are no more than a passive, unreflected outgrowth of ideological indoctrination, mental adaptation, or habituation. But this need not be the case. Even a will that is entirely fixed at present can justifiably be regarded to be "essential" if there is evidence that this fixation has resulted from earlier free choices which are still active (i.e., that have neither been retracted since nor have fallen into oblivion); it is not necessary, though, to renew the underlying deliberations and decisions constantly.

Moreover, even if existing restrictions are not dependent on earlier choice at all but are merely due to hereditary predisposition, automatization, habituation, or casual external influences, personal freedom can be preserved if the person in question is aware of the restricting facts and chooses freely to live with them. Strict necessities, whether of nature or of society, have to be acquiesced anyway as

${ }^{16} \mathrm{For}$ an analysis of various relevant factors involved in processes of this kind, see, e.g., M. Bratman (1987) and N. Roughley (2008), chs. 8-9.

${ }^{17}$ G.W. Hegel (1976), 52-57 (\$\$ 6-7). 
such necessary conditions define which basic actions and which ensuing consequences of basic actions (causal, normative, or other) may become real in principle. Hence the Stoic recommendation that we no longer want or will actions, or consequences of actions, against what is fixed and determined independently. And if there really are such things as strict "necessities of volition", as has been claimed by various recent philosophers,$^{18}$ similar recommendations of a higher order will apply to futile attempts to get rid of these, too.

Now, neither the Stoic dog running willingly alongside the cart he is tied to, nor the fabled fox resigning wilfully from his intention to eat the grapes by declaring them to be sour, are very good examples of personal freedom. Surely volitional resignation as such is no proof of volitional "essentiality". Still, there are positive instances. Having acknowledged once and for all that my talents do not suffice for becoming a solo violinist, I have given up such juvenile aspirations, consenting consciously and decidedly to lead the life of an amateur violinist whose "essential" goals are not frustrated by his limitations. Similarly, it does not touch on my sense of freedom that in deliberating and forming a settled will or intention I am guided consciously or unconsciously - by various ingrained goals, interests, tastes, and norms (political norms as well as social, moral, and aesthetic norms, etc.) which are the product not of my free decision but of the irreversible influence of my earlier education and socialization. Of course, this had been different formerly when I first came to reffect on the contingencies of my present social and cultural life and its genesis. Some of the standards which I had taken over from my parents and teachers without reflection I have dismissed as a grownup, deliberately and successfully. Others I would like to get rid of but cannot; here my volitional freedom is restrained unfortunately. But there are many norms and standards that I have chosen deliberately not to discard or to eradicate personally since I have come to accept them as an "essential" part of what I am.

Furthermore, reducing in practice the range of our alternative options is imperative or highly advisable anyway, due not only to the limited intellectual capacities of human beings in general, but also to the insuperable limitations of time and objective situational impossibilities to calculate completely the relevant means, side effects, and consequences of intended ends. As has been noted repeatedly by philosophers or tragic poets, ${ }^{19}$ deliberating too long or even knowing too much about a particular action ${ }^{20}$ may lead to a substantial loss of personal freedom by weakening, or eliminating completely, the ability to choose and decide in time Hence, it seems wise to restrict one's options. Sometimes this is done explicitly by a deliberate decision. Most often, however, actions, volitions, deliberations, and

${ }^{18}$ See, e.g. H. Frankfurt (1999), B. Williams (1995), and G. Watson (2004), 88-122. Despite all such respectable claims and arguments, I am still unconvinced by these and highly skeptical about the existence of strict "volitional necessities" (see Sect. 7 below, and, for a critique of Frankfurt's theses, E. Tugendhat (1992), 464ff., and G. Seebaß (2006), 118, 126f., 322f., 325).

${ }^{19}$ Most famous perhaps by W. Shakespeare, Hamlet, Prince of Denmark, act III, scene 1, and F. Schiller, Wallensteins Tod, act III, scene 4.

${ }^{20}$ Compare for this possibility, e.g, G.C. McCallum (1967), 331f., and I. Berlin (1978). other processes of forming the will are restricted unintentionally and without reflection, due to the influence either of prior habituation and automatization or of occasional, situational factors, both external and internal. But if these latter restrictions are to be more than a mere sign of obstinacy or narrow-mindedness, they must somehow be related to the crucial fact (whether past, present, or future) that the person in question consents to these restrictions and chooses freely not to get rid of them. Thus, so far, all positive instances of acting and willing freely appear to depend on actual choice.

\section{Freedom Dependent on Possible Choice}

Still, there are many actions and processes of forming the will which we readily take to be free and "essential" to the persons in question despite the indisputable fact that the relevant choices are missing. Philosophers such as Sartre and Locke have denied this claim, arguing that it is inevitable for rational beings to make a decision pro or con once they are confronted consciously with any concrete option..$^{21}$ Applied to the present case, this would mean that every concrete instance of acting or forming the will consciously known to be restricted or fixed without alternative must either be consented to freely by the persons in question or be disclaimed as being "inessential" and harmful to their personal freedom. I do not think that this is true in general. But even if such choices were confirmable in every conscious case, this is ruled out wherever existing restrictions are unreflected or unknown in general. Accordingly, are we to say of these latter cases that they exemplify "freedom without choice" if they are indubitable instances of freedom at all?

Clearly this would be overhasty. First, we must ask whether our willingness to ascribe "freedom" in these cases depends on the presupposition of possible rather than actual choice. If people did come to realize and reflect on the fact that their ability to choose between alternative courses of action or ways of forming the will is cut or restricted severely, would they consent to this fact as being compatible with, or even conducive to, an "essential" or "natural" form of life? And, by the same token, would they choose not to disclaim the existing restrictions or to try to get rid of them? If so, we may be justified in calling their actual (unreflectively restricted) form of living free; otherwise, this is doubtful. Modifying a well-known distinction of Aristotle's, ${ }^{22}$ we could say that personal freedom may well be compatible with acting or forming the will "in ignorance" of existing restrictions, but not "by reason of ignorance". Why? Two types of argument are relevant here. First, freedom can be denied in view of the fact that the person in question would have adopted a different stance if he, or she, would have been aware of the existing restrictions. Second, the denial of freedom can be derived from the mere fact that someone

${ }^{21}$ See J. Locke, loc. cit., bk. II, ch. 21, § 23, and J.-P. Sartre (1962), 587, 699; (1986), 28-30.

${ }^{22}$ Aristotle, Ethica Nicomachea, bk. III, 2: 1110b25-1111a1. 
unaware of existing restrictions just has no chance to make up his, or her, mind and take a personal stance whether or not this would lead, eventually, to a personal dissociation and different reaction. On both counts, many superficial examples of "freedom without choice" will turn out either to be no instances of personal freedom at all or to depend on the presupposition that relevant choices are possible.

To verify this claim, let us look first at restrictions resulting exclusively from the fact that alternatives which are actually open are unknown in general or unreflected. Consider the case of a man in a restaurant ordering a dish chosen from an incomplete list. If he had known of the unlisted options, he might have or would have chosen another dish. Regarding freedom of will, his choice is unfree, as the relevant processes of forming the will are restricted harmfully by his ignorance. Regarding freedom of action, we may be inclined to call this man free. If so, however, this is due solely to the fact that there are alternative options which could be realized objectively depending on possible alternative choices. Therefore, we have no positive instance of "freedom without choice" here.

Similar things can be said of various other cases. Consider a young Anatolian woman whose will is bound fully and strictly to the normative standards of her Muslim society. Certainly, she is not free in forming her will provided that there is a significant probability that she could, or actually would, form an intention to violate some of these norms if she were informed, for example, of the UN Convention of Human Rights and given an opportunity to make up her mind freely. Conversely, the will of a regular German car driver is not proven to be unfree by the mere fact that he acts on the steadfast, habituated intention to keep his car on the right side of the road without reflecting for a moment on the possibility that, by taking advantage of his undeniable freedom of action to turn to the left and provoke a fatal crash, he might also act, alternatively, on the recalcitrant intention to violate the rule of the road and criminal law as well. For, if he would come to reflect on this deviant possibility, it is most likely not only that he would unswervingly reject this course and consent readily to his volitional habituation, but also that he would not deny his unrestricted ability to change his will if he chose to do so.

Perhaps the car driver's case as well as the case of the Anatolian woman will also allow for a stronger interpretation. Couldn't it be the case that some of our volitional attitudes and ensuing actions are so entrenched and automatized as to rule out possible deviations outright? If so, the critical restrictions would be due not merely to the existence of subjective epistemic defects but due to the fact that the relevant options are closed objectively. There are simply no alternatives to be chosen any more. Given this scenario, can we still call the volitions and actions of persons free? Perhaps we can. But if the restrictions do not result from relevant earlier free decisions and choices, how can we tell that they are "essential" or "natural"?

Again, I think we have to rely on the criterion of possible choice. First, we must refer to relevant cases, actual or hypothetical, where the persons in question are aware of the existing restrictions and have a chance to reflect. Second, we must check carefully whether a given habit of acting or forming the will that seems unalterable at first glance, or cannot be altered readily, will turn out to be insuperable in fact if the persons in question disjoin reflectively from this habit and earnestly try to dispense with it. As has been noted repeatedly by different moral philosophers, ${ }^{23}$ not many so-called "necessities" of action or volition prove to be necessitating and determining in the strict sense if inspected more closely. Third and most important, we must inquire into the reflective processes and final reactions to restrictions which are believed, rightly or wrongly, to be unalterable. Normally, with the possible exception of strict determinism, choice is not ruled out completely on the volitional level. If someone reflecting on his volitional attitudes and established routines of forming the will can be expected to consent and identify himself freely with perceived restrictions, we can ascribe personal freedom to him. But it may well be that a man realizing, for example, how difficult it is to dispense with entrenched dispositions, prejudices, and normative standards imprinted on him by his sociocultural environment, will come to acquiesce and eventually give up any further attempts to change his condition, although he may still disjoin reflectively from characteristics considered to be "inessential" and hindering for him as a person. Certainly, such a man is not free, since he lacks the ability to choose effectively the states of volition and action considered by him to be "essential".

\section{Possible Forms of Freedom Without Choice}

Up to this point, we have not found convincing examples of "freedom without choice". Trying to specify a significant class of volitions by relying exclusively on the criterion of "naturalness" or "essentialness" (Sect. 4), we have been referred either to actual or to potential choices in turn, even if choices confined in some cases to reflective consent to, or dissent from, existing unalterable restrictions. Or else we have come to realize that individuals deprived of personal choice are unfree in some way or other. So far, then, the answer to our central question is negative. Still, there is one unexplored theoretical possibility which could allow for a positive answer. If we could find some qualified class of restrictions that human beings, taken individually or generically, cannot discard in principle but must accept as fundamental preconditions of acting and forming their will in a "natural" way or leading an "essential" form of life, we might come up with convincing, undeniable examples of acting or willing freely independent of any choice after all. However, what kinds of restrictions will qualify?

Many authors, including philosophers, have affirmed that the preservation of biological life or the satisfaction of basic needs are the dominant, indispensable goals of every human being which severely restrain the range of objects of volitions

\footnotetext{
${ }^{23}$ See, e.g., I. Kant (1902) ff., Bd. V, 30, A. Schopenhauer (1977), 82f., and for a critique of relevant recent positions, $\mathrm{G}$. Watson (2004), $93 \mathrm{ff}$.
} 
and actions possible. ${ }^{24}$ Most people will also accept these goals as "natural" and "essential" objects of their personal will, at least under normal conditions. Moreover, it seems advisable in principle (as well as wise in the Stoic sense) not to disjoin personally from the insuperable limitations of man's biological nature. Nevertheless, this move is possible and quite common. There are many examples and much written evidence of persons feeling constrained by basic needs and the limits of human biology. ${ }^{25}$ There are also many instances of persons not caring in the least for their own biological life. ${ }^{26}$ Similar observations apply to the claim that human beings are bound unalterably to the pursuit of happiness or a striving for pleasure. Although both of these goals are familiar and consented to by almost everyone at first glance, they may well be rejected deliberately on reflection. Moreover, both of these goals are notoriously unspecific and vague. Irrespective of whether traditional claims for their general, overriding importance are interpreted in a normative or descriptive way, if such claims are to have any general anthropological plausibility, the critical notions of "happiness" and "pleasure" must be defined in a manner circular with regard to the very notion at issue, viz. by referring indefinitely to whatever goals are regarded by human individuals at varying times to be an "essential" object of volition. ${ }^{27}$

Turning next to an influential idea already put forward paradigmatically by Aristotle, ${ }^{28}$ couldn't one argue that man is a social, cultural, or political being "by nature", which is to be defined, individually and generically, by a variety of fundamental, irrevocable socio-cultural traits? Obviously, this cannot mean that people will never come to emancipate themselves from the established structures and standards transferred to them by society, including deep-seated theoretical convictions and practical attitudes (vide our example of the young Anatolian woman, Sect. 6). But it may be that there is some qualified class of restricting characteristics, physical and mental as well, which human beings cannot dispense with as these

\footnotetext{
${ }^{24}$ Apart from a few exceptions (most prominent Thomas Hobbes), philosophers have not confined themselves to biological life but have included basic needs. The question of which needs are "basic" has also been answered differently and often in a very generous way. Some authors are willing to include, e.g., even the needs of addicts (see G. Watson 2004, 84ff., and J. Schälike 2010, 89f.)

${ }^{25}$ Contempt of biological limitations is exemplified by the old human dream of flying as well as by the old myths of Cockaigne or the Fountain of Youth. Indignant unwillingness to surrender to the constraints of basic needs (sleep, supply of food and water, etc.) is a common reaction of men absorbed in their strife for an exceptional goal (of sports, arts, science, etc.) and can be observed even in younger children. Moreover, Kant went so far as to claim that every man, as a rational being, must want to be freed of any natural inclinations and needs whatsoever (I. Kant $1902 \mathrm{ff}, \mathrm{Bd}$ IV, 428, 454f.; Bd. V, 86f.)

${ }^{26}$ The most blatant recent example is suicide terrorism, of course. But there have always been multifarious instances of fanaticism (or heroism, if you prefer) showing that men are quite willing to sacrifice their own lives for their country, families and closest friends as well as for their most intimate personal ideas, e.g., scientific, artistic, religious ideas, or various others.
}

${ }^{27}$ This general conclusion is plausible enough, I hope, although this cannot be argued in detail here. For a further argument in support my claim, cf. Sect. 8, note 34, below.

${ }^{28}$ Aristotle, Politica, bk. I, 2; Ethica Nicomachea, $1097 \mathrm{~b} 11$. characteristics depend in principle on antecedent, irreversible processes of education and socialization. The extent to which this is true empirically is unclear to me. Such questions cannot be answered by armchair philosophy but must be answered by empirical psychology, sociology, etc. Still, it seems plausible at the outset that some such characteristics will be found. It also seems evident that human adults can acquire the ability to reflect critically on the social and developmental aspects of their life once they have become autonomous persons, which implies, as a consequence, that it is possible for them, too, to dissociate reflectively from their contingent cultural genesis. To be sure, this dissociation may lead to a significant loss of personal freedom, in particular if we are dissatisfied with certain traits and try to get rid of them but it turns out, eventually, that we are unable to dispense with our established "social" or "cultural selves" in fact. Still, this is not the only possibility. It may well be, after a period of critical reflection, that we end up consenting reflectively to some traits acknowledged not to be harmful to us in the least as they are recognized to be essential, indispensable preconditions of our autonomy and personal freedom. If so, we may be justified, after all, to speak of "freedom without choice".

Now, if the idea of irreversible socio-cultural transfers and fixed, yet indispensable, characteristics of autonomous persons can be worked out such as to yield a convincing argument, we have to look first and foremost at the basic structures of language and rationality. Here we are most likely to find convincing evidence for the thesis that talking of "freedom without choice" is no misuse of words in some cases. Let me illustrate this point with reference to a classic example, viz. the famous words ascribed (flowerily, but incorrectly) to Martin Luther as his concluding statement at the Diet of Worms: "Here I stand, I cannot do otherwise". These words have often been referred to as a paradigm case of so-called "necessities" of volition and action. ${ }^{29}$ Yet is that really true and, if so, on what grounds? Certainly, Luther's statement was free although it had been unavoidable for him in some sense. What sense? Now, to a certain extent, the alleged "necessity" seems to derive from a practical reason not normally taken to be strictly necessitating and independent of any personal choice, i.e., from a settled moral conviction. Moral convictions are strong, but they must be adopted first and can be violated. Most probably, contrary to what is ascribed (flowerily, but dubiously) to George Washington or to the elder Cato, Luther was able "to tell a lie" but did not lie in fact since he acted on the firm intention to keep the eighth commandment. Whether this intention was formed, or renewed, at this particular moment or had been formed long before and never since called into question is immaterial to our argument. In fact, Luther may not even have applied any conscious thought to the option of lying. Rather, the central point for us is this: interpreted as an act of moral obedience (even of strict, "categorical" obedience), Luther's free and unavoidable action of telling the truth does not instantiate "freedom without choice"; quite to the contrary, it is an instance of "freedom with choice", if even merely possible choice (Sect. 6) or choice made at an earlier time (Sect. 5).

${ }^{29} \mathrm{Cf}$. note 18 above and for some relevant recent references to Luther's dictum G. Watson (2004) $100 \mathrm{ff}$. 
Still, there is another sense in which Luther's statement appears to be necessary. The main reason why he "could not do otherwise" seems to have been an instance of theoretical rather than practical rationality. After a long course of intensive studies, Luther had come to the conviction that certain theological propositions are true although they are rejected by the authorities. As a rational being, he was unable to avoid accepting the results of reasonings based on evidence taken by him to be conclusive. However, are we to say that this acceptance was necessitated or determined strictly? This would be rash, indeed. Initially, Luther himself had been forced to accept his new and deviant theological conclusions against his reluctant will. So, one might think that it is possible after all to deny oneself even to cogent theoretical arguments or to the very standards of theoretical rationality. ${ }^{30}$ Moreover, Descartes has claimed that it is possible to produce false beliefs at will, even if there is evidence to the contrary. ${ }^{31}$ However, to the extent that such claims have some plausibility, this is due to the fact that the evidence given is not conclusive and there is room for doubt. Otherwise, it is not possible to disjoin radically from the consequences of one's rational theoretical insight, I think. Being truthful to others is, or can be, a matter of choice and free decision under normal conditions, whereas accepting truth is not. And, to the extent that the relevant processes of forming the will are restricted by rational theoretical insight, one cannot argue that the resulting volitions are "inessential" and detrimental to personal freedom. So we have found some sense after all in which we may justifiably speak of "freedom without choice".

To a lesser degree, this applies to practical rationality, too, provided that this not identified simply with acting intentionally on given moral standards. Certainly, it is not strictly necessary to act in accordance with one's "best considered will", even if this will has resulted from a long and sophisticated process of practical deliberation and has never been called into question since. For, under normal conditions, it will still be possible to take up deliberation again, to reconsider and change one's mind instantly, if there is any time left to do so. And this holds true even in case one has already formed a settled intention, provided that the corresponding intentional actions either have not been started yet, or else have not been automatized to a degree that does not allow for an interim stop anymore. Akrasia is possible after all, and a common experience. ${ }^{32}$ Still, there is some truth to the old Socratic denial of akrasia. What seems impossible in fact is trying to dissociate oneself rationally from the conclusions of (valid) practical inferences as long as one does not dissociate also from (some of) the relevant premises. Having decided spontaneously and freely, for example, to go to a concert tonight and having realized that this implies two further decisions of mine, viz. to leave my home in time and to miss

\footnotetext{
${ }^{30}$ Note that the very talk of a "cogent" argument seems to convey a sense of overwhelming "rational compulsion" which a free man possibly might deny.

${ }^{31}$ At least this is claimed for evidence not entirely "clear and distinct" (see R. Descartes 1999, vol. I, 204, 205f., 207; vol. II, 39ff., 45, 48; vol. III, 244-246, and for a critical discussion A. Kenny (1972)).

${ }^{32}$ For a detailed analysis of intentions and intentional action relevant to these points, see $\mathrm{N}$.
} Roughley (2008), pt. II, and, for a relevant account of akrasia, G. Seebaß (2005). a particular program on television, I cannot disown these latter decisions as long as I refuse to revoke and deviate from my primary decision, too.

However, the practical case is much more ambiguous than the theoretical one. Consider once more our last example. If I thought, or came to think, that the TV program competing with tonight's concert could be important to me, I might take up deliberation again and end up, eventually, either confirming or revising my spontaneous first decision. Both results could be arrived at freely and in accord with my unreserved, wholehearted consent to the fact that, as matters stand, I have no choice but to miss either the concert or the TV program tonight, although I can choose which. In this respect, my resulting will and ensuing action could be an instance of "freedom without choice". However, this is not necessarily so. Alternatively, I could also disjoin myself discontentedly from a state of the world which has come to pass independent of any choices of mine, whether factual or potential, and which does violence to my personal freedom as it confronts me with a hopeless dilemma considered by me to be offensive, alienating, and, therefore, "inessential". 33 Thus, under certain conditions, practical rationality will provide positive examples of "freedom without choice", too. Yet this is possible only relative to the (expressed or tacit) presupposition that the objective circumstances restraining personal choice are consented to freely and that the volitions guiding, or resulting from, relevant practical deliberations are "natural" or "essential" to the person in question.

Finally, what about language? Traditionally, language is considered to be the most prominent mark of humanity and an essential precondition of reflection and rational deliberation. So it seems senseless from the start that human beings should try to dissociate themselves wilfully from the basic structures of language. This diagnosis is confirmed by everyday practice. Normally, we do not feel unfree or hindered substantially by the fact that we cannot alter language at will. Normally, we have no choice but to stay with basic linguistic structures, not only with the inherited fundamental structures of an entire language group (e.g., the Indo-European group), but also with the majority of the more specific peculiarities of our native tongue or dialect. Nor have we had any chance in infancy to deliberate in advance and to choose freely which particular language we should learn. Accordingly, these aspects of our personality and socio-cultural genesis are least likely to be disowned reflectively, if they are reflected and called into question at all. Hence it seems clear that the basic structures of language and corresponding linguistic abilities of human grownups are qualified to provide positive examples of unalterable social and cultural characteristics which are not harmful to us in the least but indispensable for our personal freedom, although they may imply a severe restriction of options and are not subject to choice at all, neither factual nor potential.

${ }^{33}$ Of course, the impossibility to attend concerts and TV programs at the same time is not normally thought to be "unnatural" and detrimental to human freedom. Here my discontented personal reaction to an unhappy temporary coincidence would seem to be immoderate or grossly exaggerated. Still, there are other cases where such reactions are justified. To take an extreme case, think of a really cruel dilemma which might be created by relentless nature as well as by criminal human intent, e.g., the dilemma to sacrifice either your own life or the life of your beloved child or spouse. 
Still, to a certain extent, personal dissociation is possible even here. Poets and various other writers have often described the pain of finding appropriate expressions and have deplored, accordingly, the untoward semantic restrictions of language. Similar complaints are raised by translators. Of course, by learning a foreign language we may transgress our native tongue and enlarge our linguistic competence. But this option has notorious limits. Moreover, it is not to be expected that the linguistic structures of various languages add up smoothly to form an all-inclusive semantic scheme. Some significant, incompatible differences will always be left. On the other hand, it is most likely that certain formal structures (predication, negation, contradiction, modes, etc.) are common to all existing languages and cannot be transgressed in principle. Now, to the extent that people are able to form a sensible want or will to go beyond a given linguistic frame, they are in a position to disjoin mentally from significant parts of their basic socio-cultural heritage. Realizing, however, that normal human beings have no choice but to stay with most of them, some people may conclude that the restrictions resulting from insuperable linguistic bonds are hindering and detrimental for their personal freedom. Still, this reaction is not the only one and confined, moreover, to a very limited class of cases. For, reflecting critically on the limitations of language and of our personal linguistic competence is a rational enterprise itself which depends (as noted before) on the use of language in turn. Therefore, in trying to carry out such activities and in trying to form, eventually, a disjoining volitional attitude, we have to rely on established linguistic abilities that we cannot call into question at the same time. At this level of critical reflection, or some relevant higher level, any proclaimed attempts at dissociating oneself from the basic structures of language are without sense, and so are all claims to a corresponding loss of personal freedom. Consequently, to the extent that the thesis is justified that human beings have a personality constituted by language and by fundamental linguistic competencies which they cannot transgress in principle, it is no misuse of words to say that human individuals may exemplify "freedom without choice".

\section{Conclusion}

So we have found, after all, several significant cases where choice is eliminated due to the inexistence of accessible alternative possibilities but where it is justified, nevertheless, to call a particular person "free" relying exclusively on our second criterion, the criterion of "naturalness" or "essentialness" (cf. Sect. 2). As we have seen, this applies first and foremost to the basic structures of language and rationality, at least to the extent that such structures can reasonably be conceived to be formal preconditions of personal freedom and autonomy. This is all the more plausible if the very notions of "autonomy" or "personal freedom" are defined in a formal manner, viz. as abilities of persons to reflect, deliberate, form a considered rational will, decide for a particular course of action, and act intentionally on these decisions. Still, one might think that personal freedom is not exhausted by its formal aspects. Drawing from the Aristotelian idea of man as a social being "by nature" as well as from some more recent ideas of a "Hegelian" or "communitarian" brand, various philosophers have conjectured that arguments similar to the formal arguments just given (Sect. 7) will apply to the contents of "social" or "cultural selves", too, including a substantial number of political, legal, and moral norms transferred to us by society. This could be a charming idea, indeed, although it would be a somewhat disquieting idea at the same time. However, are there any arguments of the required type? I do not want to object to the idea in principle. Yet I am highly skeptical about its force and empirical significance for the following reasons.

First, we must not confuse demanding claims for normative variants of "freedom without choice" with the uncontroversial, almost trivial thesis that there are many norms of human societies (criminal laws, laws of tort, traffic rules, etc.) which may entail a severe restriction of individual options but are, nevertheless, conducive to, or even necessary for, social freedom, i.e., freedom understood as a common good to be secured and distributed among the members of a society. Norms of this latter kind are ill-suited to the task of discovering relevant examples of "freedom without choice". For one thing, most of these norms do not extend to freedom of will but are confined to freedom of action. Moreover and most importantly, if personal freedom can justifiably be ascribed in these cases, this is due merely to the (explicit or implicit) presupposition that the individuals in question have not been deprived of the ability of free consent and choice, whether actual or potential (Sects. 5 and 6). At the very least, they must be able to choose (1) between accepting or disjoining personally from the fact that, as members of a particular society, they are subject to various norms designed to cut individual freedom in favor of distributive freedom. And it is highly plausible to add that they must also be able to choose (2) between violating or complying with particular norms and (3) between staying or leaving this society altogether. Otherwise, it would be sheer paternalism, or even verbicide, to call individual persons "free" despite the fact that they could be, or actually are, unwilling to consent, or that they may be deprived of any chance to make up their mind and consent willingly, if even on grounds no stronger than fatalistic ("Stoic") resignation.

Second, paternalism is all the more imminent if one proceeds to include freedom of will but tries to specify what this means for particular persons independent of their actual or potential consent, viz. from an external position ignoring their volitional states completely (cf. Sect. 4). Here if anywhere we should be on our guard. In particular, external ascriptions of "social selves" or "cultural identities" bound to inherited religious, moral, political, or cultural norms are likely to be rash, manipulative, or simply ideological, as already illustrated by our example of the young Anatolian woman (Sect. 6). In fact, is there any feasible way to justify rationally authoritative verdicts to the effect that the following belongs to the "nature" or "essence" of a particular person: to have a will fixed without alternative to certain normative standards, e.g., to the goal of respecting the autonomy of other people or of complying unreservedly with the dominant religious or cultural standards of society? Perhaps there is. If so, however, it is most improbable that rational arguments to this effect will be able to avoid relying on the premise 
again that the person in question is free to choose and has chosen in fact (or will choose, or would choose eventually on reflection) not to disjoin volitionally from the relevant social norms. This is certainly far off from demonstrating "freedom without choice".

Third, it is of little avail, either, to bolster up authoritative ascriptions of freedom by the (expressed or tacit) assumption that the authorities in question are in a position of "knowing better" what befits individuals as members of a particular culture or society, or as social beings in general. For, is it for sure that the standards on which this presumed knowledge must rely are relevant to freedom at all and not just to what is good for particular persons or valuable for human beings in general? To be sure, freedom is highly valuable itself. But personal freedom may not be the only, or most important, part of what is constitutive of a good or valuable form of life. Now, I do not think that there are any human values of a higher rank than the value of personal freedom, and I am rather skeptical that there are human values reasonably supposed to be of an equal rank which cannot be shown to depend, explicitly or implicitly, on the value of freedom in turn. ${ }^{34}$ For a quick test of this claim try, if you like, some values traditionally thought to be competing with personal freedom, such as happiness, pleasure, health, wealth, security, justice, equality, patriotism, public spirit, love, friendship, wisdom, or what have you. Still, for the sake of argument, let us suppose that there are certain values independent of freedom and having an equal, or even higher rank. If so, it may well be that it is the esteem of these values rather than the value of personal freedom which gives external ascriptions of "social selves" and "cultural identities" all of the rational plausibility such ascriptions may have. In this case, we will not have found any new instances of "freedom without choice" at all, although we may have found some socio-cultural variants of "personality without choice". But, to the extent that normative characteristics and other non-formal socio-cultural traits can reasonably be interpreted to be conceptual specifications of the criterion of "naturalness" or "essentialness" defining of personal freedom, it is highly dubitable that characteristics of this kind should not be accessible to reflection and deliberation and should not be subject to some form of (actual or potential) personal choice, too.

At any rate, it is obvious that indubitable cases of "freedom without choice" are rare and do not allow for ready extensions or generalizations. Normally we cannot benefit from our earlier supposition (Sect. 4) that it is possible to confine to the criterion of "naturalness" but must recur to the criterion of open possibilities in addition. The reason for this is clear. If the range of possible actions or volitions open to us in fact is restricted severely or, in the extreme (determinist) case, reduced to a single possibility, our personal freedom is lost. More precisely, it is lost just to the extent that we have lost the fundamental ability to define what is "essential" or "inessential" to us by choosing between alternative possibilities and deciding freely for a particular option. Also, it should be clear that this ability refers to cases of real

\footnotetext{
${ }^{34} 1$ have argued for these claims in detail in G. Seebaß (2006), ch. 9
}

choice, i.e., choice between alternatives objectively open. It does not refer to subjective or merely epistemic "quasi-choices" or "quasi-decisions" deprived of any ontological significance, an idea put forward by various writers which we have rejected before (Sect. 3). Accordingly, real friends of freedom should face up to this fact and not foster any longer the soothing illusion that the question whether universal determinism is true, or might well be true, is immaterial to understanding ourselves as free and autonomous persons.

\section{References}

Benjamins, H.S. 1994. Eingeordnete Freiheit, Freiheit und Vorsehung bei Origenes. Leiden: E.J. Brill.

Berlin, I. 1978. From hope and fear set free. In Concepts and categories, 173-198. London: Hogarth Press.

Bratman, M. 1987. Intention, plans, and practical reason. Cambridge: Harvard University Press. de Molina, L. 1988. In One divine foreknowledge, ed. A.J. Freddoso. Ithaca/London: Cornell University Press.

Descartes, R. 1999. The philosophical writings of Descartes, vols. I-III. Cambridge: Cambridge University Press.

Frankfurt, H. 1988. The importance of what we care about. Cambridge: Cambridge University Press. Frankfurt, H. 1999. Necessity, volition, and love. Cambridge: Cambridge University Press. Fromm, E. 1941. Escape from freedom. New York: Holt, Rinehart and Winston.

Gaskin, R. 1993. Conditionals of freedom and middle knowledge. The Philosophical Quarterly 43: $412-430$.

Hegel, G.W.F. 1976. Grundlinien der Philosophie des Rechts. Repr. Frankfurt: Suhrkamp.

Hobbes, Th. 1966. The English works, vols. III-V, ed. W. Molesworth. Repr. Aalen.

Huxley, A. 1936. Eyeless in Gaza. London: Chatto \& Windus.

Kant, I. 1902 ff. Gesammelte Schriften (Akademie-Ausgabe), Bde. IV-V. Berlin: Reimer.

Kenny, A. 1972. Descartes on the will. In Cartesian studies, ed. R.J. Butler, 1-31. Oxford: B. Blackwell.

MacKay, D.M. 1967. Freedom of action in a mechanistic universe. Cambridge: Cambridge University Press.

McCallum, G.C. 1967. Negative and positive freedom. Philosophical Review 76: 312-334.

Moore, G.E. 1965. Ethics. Repr. Oxford: Oxford University Press.

Planck, M. 1965. Vorträge und Erinnerungen. Repr. Darmstadt: Wissenschaftliche Buchgeselischaft. Roughley, N. 2008. Wanting and intending. Dordrecht: Springer.

Rousseau, J.-J. 1977. Politische Schriften, Bd. 1. Paderborn: Schöningh.

Rousseau, J.-J. 1990. Diskurs uiber die Ungleichheit/Discours sur l'inégalité. Paderborn: Schöningh.

Rowe, W. 1964. Augustine on foreknowledge and free will. The Review of Metaphysics 18: 356-363.

Sartre, J.-P. 1962. Das Sein und das Nichts. Hamburg: Rowohlt.

Sartre, J.-P. 1986. Ist der Existenzialismus ein Humanismus? In Drei Essays, 7-51. Frankfurt/Berlin

Schälike, J. 2010. Spielräume und Spuren des Willens. Paderborn: Mentis.

Schopenhauer, A. 1977. Preisschrift über die Freiheit des Willens, Bd. VI, 41-142. Repr. in: Zürcher Ausgabe: Diogenes.

Seebaß, G. 1993. Wollen. Frankfurt: V. Klostermann

Seebaß, G. 1997. When is an action free? In Contemporary action theory, vol. I, ed. G. HolmströmHintikka and R. Tuomela, 233-250. Dordrecht: D. Reidel.

Seebaß, G. 2005. Akrasie. In: Enzyklopädie Philosophie und Wissenschaftstheorie, Bd. I, 59-63.

Stuttgart: Metzler. 
Seebaß, G. 2006. Handlung und Freiheit. Tübingen: Mohr Siebeck.

Seebaß, G. 2007. Willensfreiheit und Determinismus, Bd. I, Die Bedeutung des Willensfreiheitsproblems. Berlin: Akademie.

Snell, C.W. 1789. Ueber Determinismus und moralische Freiheit. Offenbach: Weiss und Brede.

Tugendhat, E. 1992. Philosophische Aufsätze. Frankfurt: Suhrkamp.

Watson, G. 2004. Agency and answerability. Oxford: Clarendon.

Widerker, D. 2006. Libertarianism and the philosophical significance of Frankfurt scenarios. The Journal of Philosophy 103: 163-187.

Williams, B. 1995. Moral incapacity. In Making sense of humanity, 46-55. Cambridge: Cambridge University Press.

Zagzebski, L.T. 1991. The dilemma of freedom and foreknowledge. Oxford: Oxford University Press. 